\title{
HOSPITAL LOGISTICS OF PATIENT FLOW: A REVIEW OF THE SCIENTIFIC PRODUCTION OF THE THEME, BASED ON A BIBLIOMETRIC SURVEY
}

Semana Online Científica de Engenharia, 1a edição, de 25/10/2021 a 27/10/2021

ISBN dos Anais: 978-65-81152-19-2

\begin{abstract}
BACELLAR; Fernanda Losso ${ }^{1}$
\end{abstract}
\section{RESUMO}

Given the importance of the implementation and contribution of the logistic in hospital institutions, as it plays the role of materials flow management, information and patients, since a failure in the logistics functions, can lead to an irreparable disaster for both patients and hospital. In this sense, the research's objective with the realization of the conceptual approaches present in the literature of hospital logistics, through a systematic review of the bibliography. Following a Systematic Literature Review (SLR) protocol, it consists of identifying the main methods adopted in the flow of patients, with a focus on outpatient care. In the database, for the survey of articles were: Web of Science and Scopus, in order to identify the indexed publications. The results revealed the conceptual divergence of the patient's flow activities that involves hospital logistics, due to the variety of activities described as logistics, from the traditional ones, present in the industrial logistics literature, to other activities that involve specific areas of the hospital.As a contribution the research sought to collaborate with the disclosure, deeper discussions and make it easier for researchers and managers to understand.

PALAVRAS-CHAVE: hospital logistics, patient flow, outpatient care, systematic literature review 